\title{
The Key Technology Research on Automatic Monitoring and Remote Controlling of Water and Fertilizer on Banana
}

\author{
Lingling Wang ${ }^{1,2, a}$, Hongxia Luo ${ }^{1,2, b}$, Jihua Fang ${ }^{1,2, e}$ \\ ${ }^{1}$ Institute of Information and Technology, Chinese Academy of Tropical Agricultural Sciences, \\ Danzhou, China; \\ ${ }^{2}$ Key Laboratory of practical research on tropical crops information technology in Hainan, \\ Danzhou, China. \\ azishi-010@163.com, b120081008@163.com, cfangdil@163.com
}

Keywords: Banana; Fertigation; Automatic Monitoring; Remote Controlling

\begin{abstract}
This paper discusses the necessity and importance of technology of drip irrigation of integral control of water and fertilization. Firstly, research situation at home and abroad of agricultural information and technology on water and fertilize controlling, agricultural production management, environment monitoring and platform for agricultural expert system is presented in this thesis. Secondly, Key technologies on automatic monitoring and remote controlling of water and fertilizer on banana are analyzed emphatically, which contains four aspects: key technology of banana soil parameter automatic monitoring, key technology of banana growth parameter automatic monitoring, key technology of the model of water and fertilizer regulation, and key technology to implement system of automatic monitoring and remote controlling of water and fertilizer on banana. At last, the paper summaries that the technology of drip irrigation of integral control of water and fertilization will be improved continuously with dramatic development of information technology, which can also lead to great changes in agriculture industrial advantages and benefits.
\end{abstract}

\section{Introduction}

Technology of drip irrigation of integral control of water and fertilization is one of the most important measures to improve water use efficiency under protected cultivation, which is an important technology to save water, economize fertilizer and protect the environment. In order to improve banana automation level, water and fertilizer-saving efficiency and promote the development of agricultural modernization, we should bring greater attention to agricultural information techniques, and enhance the research and application of advanced intelligent control techniques and decision-making sustainment. The research on the system of automatic monitoring and remote controlling of water and fertilizer on banana helps to achieve standardized management of banana orchard, save resources, improve work efficiency and eliminate unstable yielding. These works can fulfill the goals of water and fertilization management efficiently and quickly. The extension and application of these techniques successfully in large areas has a very far-reaching significance for both China and the rest of the world.

\section{Research Status}

The application of information techniques in agricultural production management is more and more widespread. Peets $\mathrm{S}$ et al. have established farm management information system applied for agricultural production management on private farms ${ }^{[1-2]}$. Farm financial condition, characteristic farm products and market information can be released over the network. The system has functions of information acquisition, expert decision and intelligent farm machinery management based on spatial information application technology ${ }^{[3-6]}$.

Because of the short history, starting late and insufficient experiences of agricultural modernization in China, the overall level of in agriculture irrigation is lower and the condition of environmental monitoring is poor. It is imperative to improve and raise the technique in drip 
irrigation of integral control of water and fertilization. Up to now, there are many domestic studies on it, including ecological balanced fertilization model, field precision fertilization decision support system, water-saving irrigation, field intelligent irrigation control system, and so on. These studies relate to wheat, rape, tomato and cucumber. But the automation and the identify result is not very good. Lansheng Deng et al. have studied technology of drip irrigation of integral control of water and fertilization on banana ${ }^{[7]}$. According to the number of banana leaves, fertilizer application and stage are determined in banana entire life cycle. After fertilizer is dissolved in water, it will be taken directly to the plant root zone through drip irrigation system by irrigation water.

Developing modern agriculture is the inevitable choice to quicken the Chinese agriculture development. It is also a fundamental way to solve our three rural problems: peasants, agriculture and rural areas. Space technology, mobile internet, Internet of Things, automation technology and other information technology are fully applied to agricultural production management, including information monitoring, expert decision, intelligent management, and prediction and forecasting. The application of agricultural information technology will step into a period of great development.

\section{Key Technology}

Key technology of banana soil parameter automatic monitoring. Using sensor technology, the measurement of soil moisture, soil nutrient, air temperature and humidity can be realized to measure rapidly and accurately ${ }^{[8-9]}$. Using GPRS, hardware inter-face technique and the corresponding communication software, wireless long way data transmission can be realized. The system of soil parameter automatic monitoring is composed of soil and air environment sensors, GPRS and database. Monitored data is standardized and directly transmitted from sensors to a secure database using the Internet. Key technology of banana Soil parameter automatic monitoring is as shown in Figure 1.

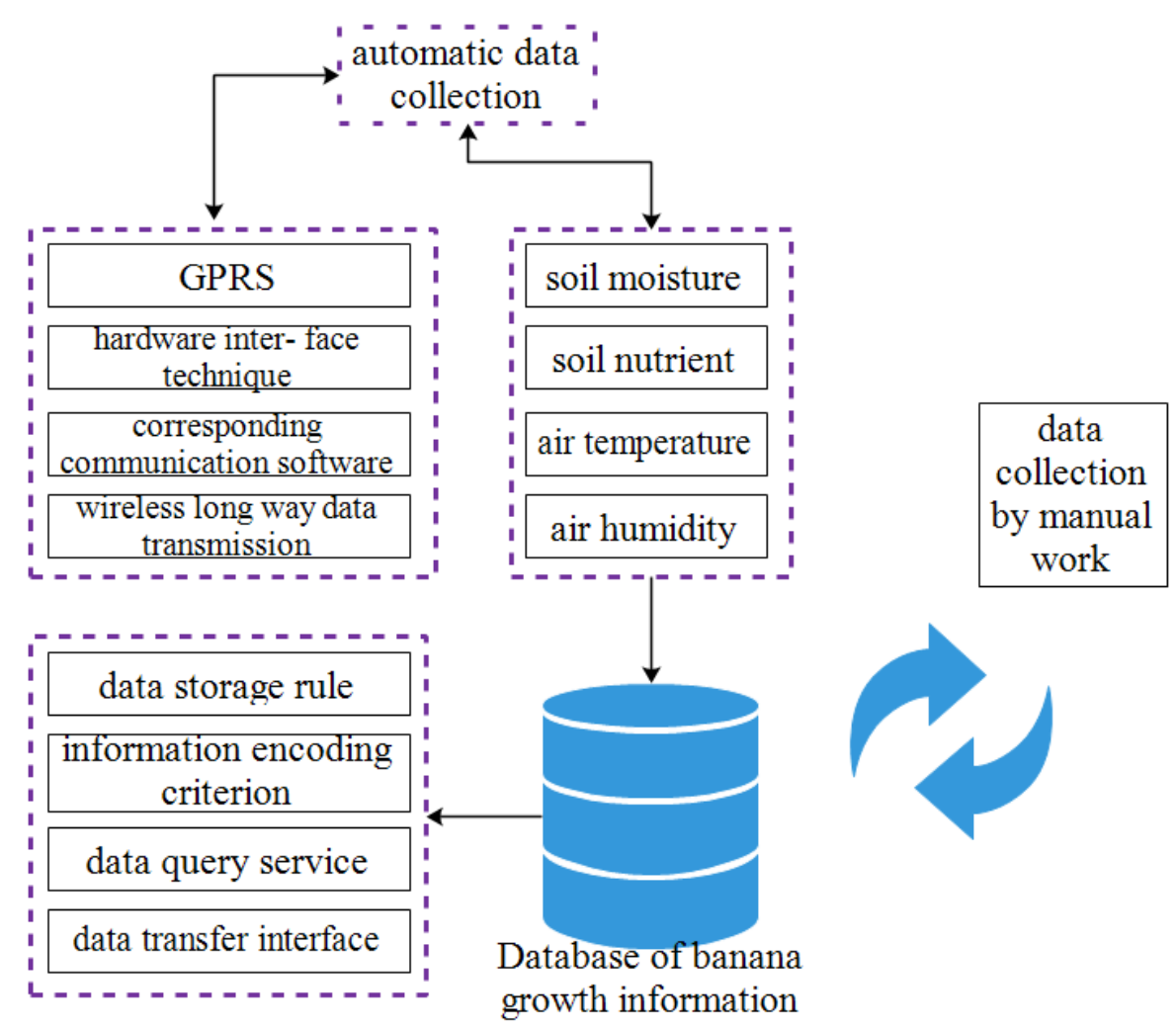

Fig. 1 Key technology of banana soil parameter automatic monitoring

Key technology of banana growth parameter automatic monitoring. Using sensor and wireless sensor technology with observation, banana plant height, stem diameter, root distribution, leaf area index, petiole length and number of leaves can be measured in the whole process of 
banana growth. Linear regression model method can be set up by utilizing statistical between banana mineral nutrition and its growing. It is especially important to set up database about the information of crop growth. Moreover, the controlling center is able to add, modify and check banana growing information, which reinforces the controlling system of field environment. Key technology of banana growth parameter automatic monitoring is as shown in Figure 2.

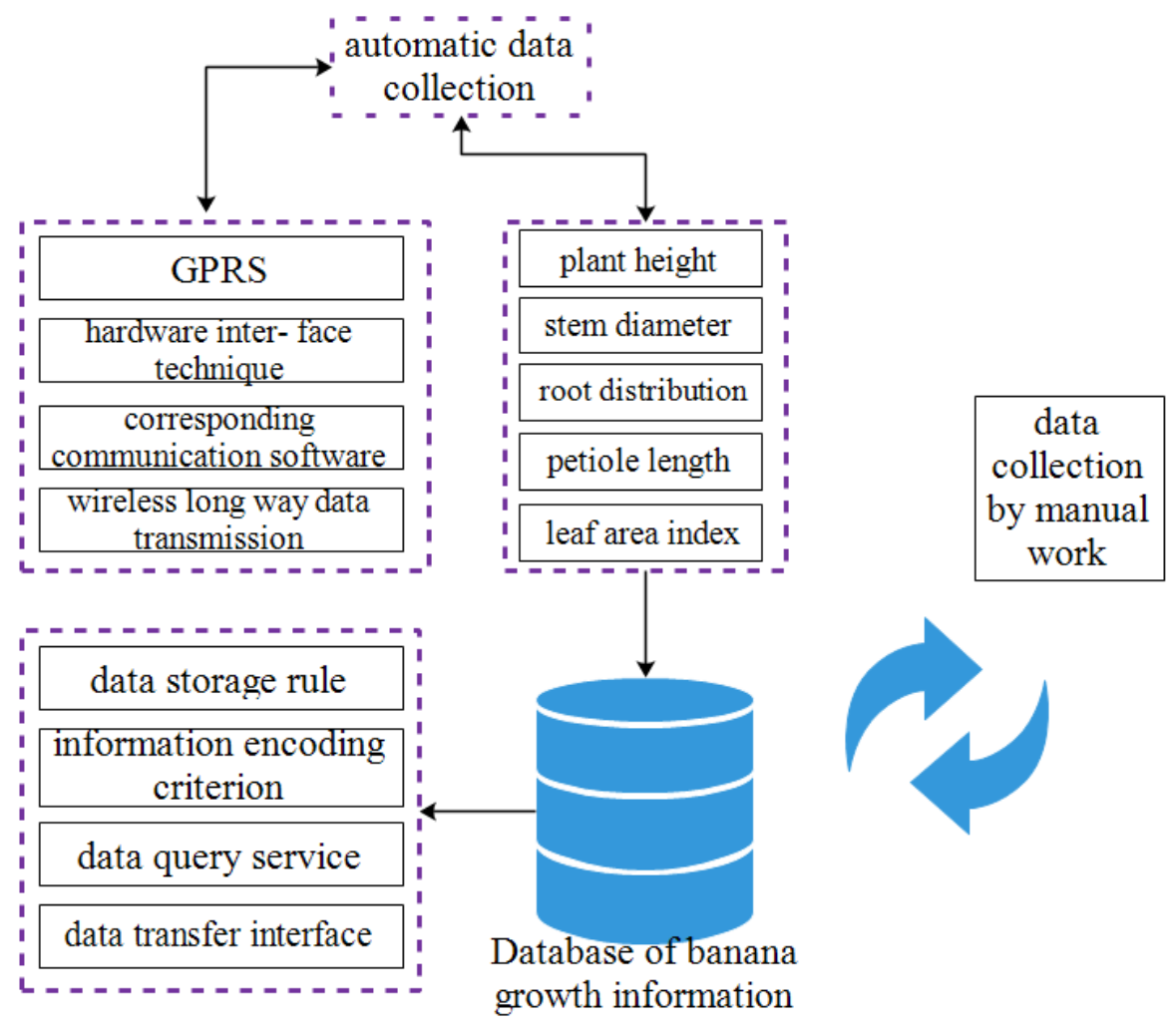

Fig. 2 Key technology of banana growth parameter automatic monitoring

Key technology of the model of water and fertilizer regulation. Our focus is on studying the relationship between banana water and fertilizer demand, growth, soil, and atmospheric environment. In order to regulating the use of water and fertilizer, we need data collection and statistical analysis. The resulting data will be used to build a mathematical model of the use of water and fertilizer on banana. According to the linear and stochastic theory of mathematical programming, a direct iterative algorithm will be constructed. The model is described as follows.

$\mathrm{F}=\mathrm{K}_{1} \mathrm{X}_{\text {banana }}$ growth $+\mathrm{K}_{2} \mathrm{Y}$ soil parameter $+\mathrm{K}_{3} \mathrm{Z}$ atmospheric environment parameter

$\mathrm{K}_{1}$ is the impact factor of banana growth. $\mathrm{K}_{2}$ is the impact factor of soil parameter. $\mathrm{K}_{3}$ is the impact factor of atmospheric environment parameter. $\mathrm{X}$ is the model of banana growth including banana plant height, stem diameter, root distribution, petiole length and number of leaves. Y is the model of soil parameter including soil moisture, soil nutrient. $\mathrm{Z}$ is the model of atmospheric environment parameter including air temperature and humidity.

The research on the control system of water and fertilizer use needs to draw support from the new technical development contents of computer software and theory, computer interface technology, communications technology, electronic display technology and automatic inspection technology ${ }^{[10-11]}$. Results in computer are presented in the forms of table, chart and graph. Manager or executer can deposit and extract the information consistently, interactively from different point, and quickly make decisions, which can make water valve or electric machine operate. Key technology of the model of water and fertilizer regulation is as shown in Figure 3. 


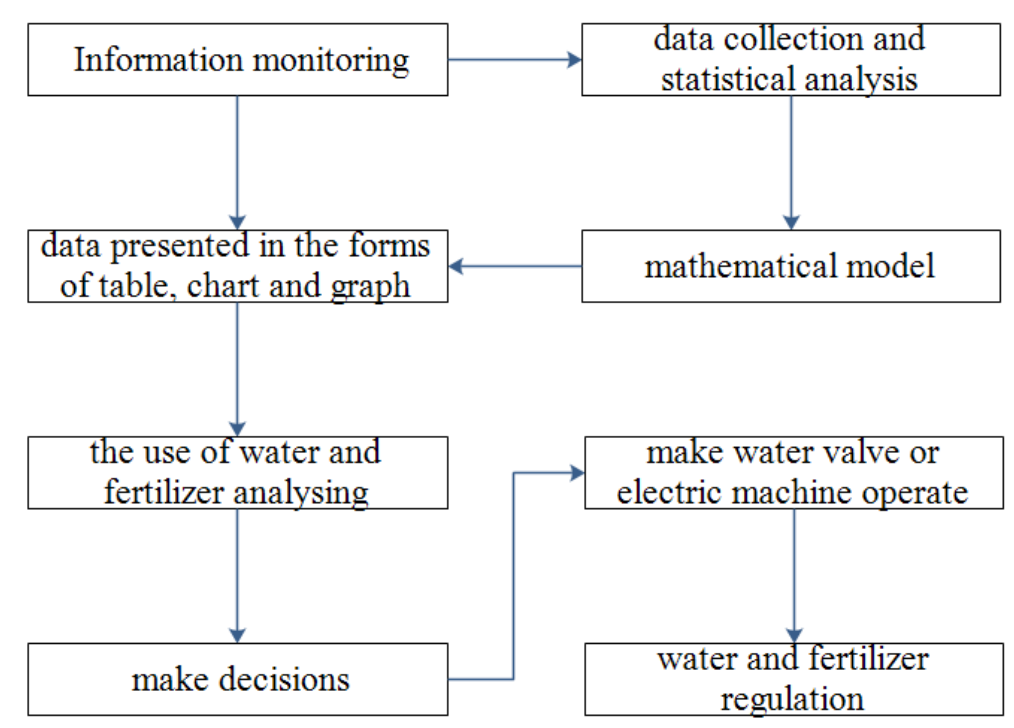

Fig. 3 Key technology of the model of water and fertilizer regulation

Key technology to implement system of automatic monitoring and remote controlling of water and fertilizer on banana. With adopting technology of embedded system, GPRS, assembly language programming and network technology, connections to the database from multi-sensor interface can be designed. All of the irrigation and fertilization system components have micro-controllers that transmit their status data to the energy management system that controls them. Key technology to implement system of automatic monitoring and remote controlling of water and fertilizer on banana is as shown in Figure 4.

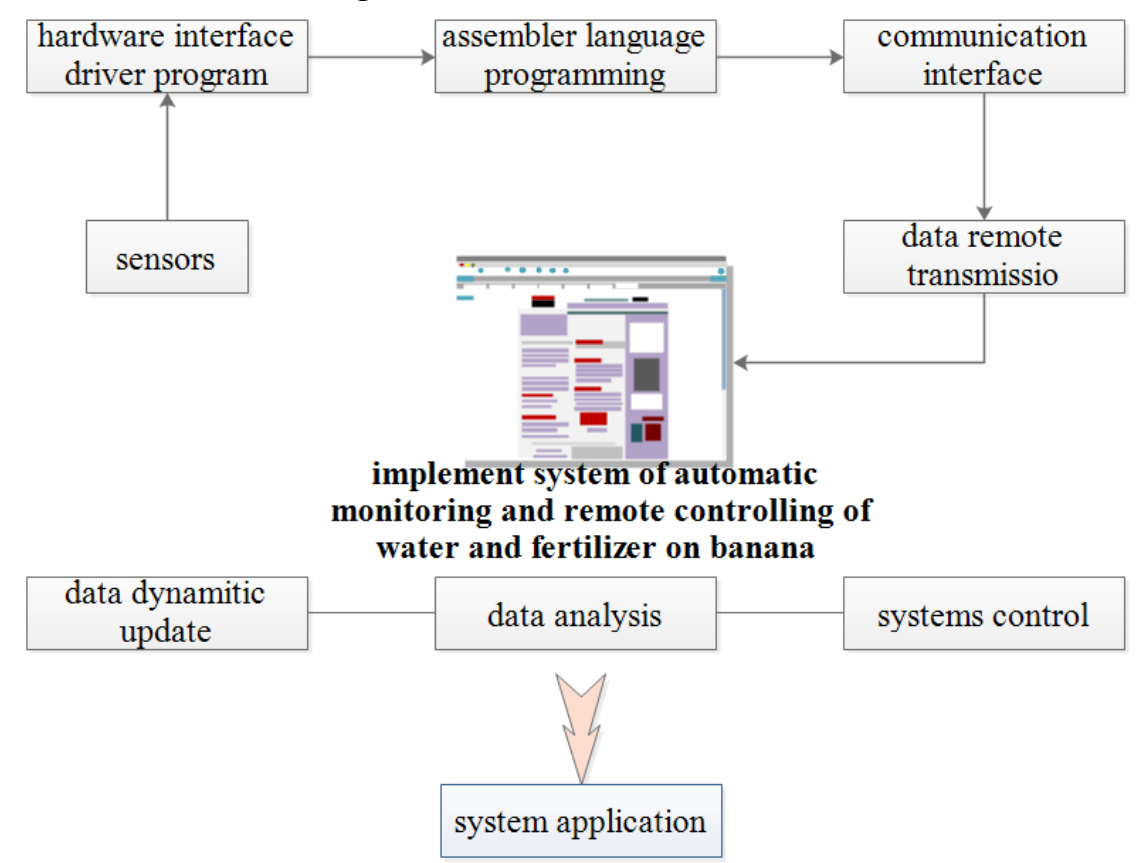

Fig.4 Key technology to implement system of automatic monitoring and remote controlling of water and fertilizer on banana

\section{Conclusion}

Applications of system of drip irrigation of integral control of water and fertilization are very useful to fertilize and water banana regularly and quantitatively. According to parameter change of soil water potential, radiation dose, banana growth information and environmental information, control scheme on the supply of water and fertilizer will be modified. The system can realize intelligent control on use of water and fertilizer. Banana can absorb fertilization and water times 
increasing so as to achieve the goal of environmental protection, reduce soil contamination and increase the yield and quality. The history data on irrigation, fertilization and environment can provide a powerful base for farmer to improvement management method.

\section{Acknowledgement}

In this paper, the research was sponsored by the Nature Science Foundation of Hainan Province (Project No. 613172) and the Fundamental Scientific Research Funds for Chinese Academy of Tropical Agricultural Sciences（Project No. 1630012015020）.

\section{References}

[1] Peets S, Mouazen A M, Blackburn K, Kuang B, Wiebensohn J. Methods and procedures for automatic collection and management of data acquired from on-the-go sensors with application to on-the-go soil sensors. Computers and Electronics in Agriculture, 2012, 81:104-112.

[2] Nikkila R, Wiebensohn J, Nash E, Seilonen I, Koskinen K. A service infrastructure for the representation, discovery, distribution and evaluation of agricultural production standards for automated compliance control. Computers and Electronics in Agriculture, 2012, 80:80-88.

[3] Sorensen C G, Pesonen L, Bochtis D D, Vougioukas S G, Suomi P. Functional requirements for a future farm management information system. Computers and Electronics in Agriculture, 2011, 76(2): 266-276.

[4] Sorensen C G, Pesonen L, Fountas S, Suomi P, Bochtis D, Bildsoe P, Pedersen S M.A user-centric approach for information modelling in arable farming. Computers and Electronics in Agriculture, 2010, 73(1): 44-55.

[5] Sorensen C G, Fountas S, Nash E, Pesonen L, Bochtis D, Pedersen S M, Basso B, Blackmore S B. Conceptual model of a future farm management information system. Computers and Electronics in Agriculture, 2010, 72(1): 37-47.

[6] Nikkila R, Seilonen I, Koskinen K. Software architecture for farm management information systems in precision agriculture. Computers and Electronics in Agriculture, 2010, 70(2): 328-336.

[7] Lansheng Deng, Panfeng Tu, Chenglin Zhang et al. Application ofFertigation Technology in Banana. Journal of Anhui Agriculture Science 2011,39(25):15306 -15308.

[8] Lingling Wang, Jiajian Huang, Shaojie Weng. The Research of Acquiring Field Information about Characteristic and Tropical Farming based on RFID, Transactions of the CSAE, 2010,26(supp.2): :98-102.

[9] Lingling Wang, Kun Lu, Hongxia Luo, Jihua Fang. The Key Technology Research on Information Acquisition about Tropical Crop Production Environment. Advanced Materials Research Vols. 989-994 (2014) pp 3452-3455.

[10] Lingling Wang, Hongxia Luo, Jianhua Cao, et al.The design of Intelligent Monitoring System on Tropical Greenhouse Crop Production Environment. Advanced Materials Research Vols. 1073-1076 (2015) pp 530-534.

[11] Jianhua Cao, Lingling Wang, Hongxia Luo, et al. A Research on Information Management System About the Field Environment of Tropical Crop, Advanced Materials Research Vols. 1073-1076 (2015) pp 3013-3016. 